\title{
CÂNCER DE MAMA: ANÁLISE DA MORTALIDADE E PERSPECTIVA DE TRATAMENTO
}

\author{
Jéssyka Samara de Oliveira Macedo I \\ Lucas Evangelista Lima Terceiro "I \\ Bruna Braga Dantas
}

\section{RESUMO}

A taxa de mortalidade (TM) representa um dos principais indicadores da qualidade da assistência a pessoa com câncer de mama (CM), mostrando-se como um instrumento fundamental no delineamento e revisão das políticas voltadas a pessoa, acometida pela doença. A abordagem terapêutica, por sua vez, representa um dos eixos primordiais à redução da mortalidade pela doença. Assim, o objetivo deste estudo é caracterizar o perfil da mortalidade por CM no Brasil, bem como propor uma nova alternativa terapêutica, baseada no uso de produtos naturais. Para isso, realizou-se um estudo documental-retrospectivo, descrevendo a distribuição da TM por CM no Brasil, durante o período de 1987 a 2016, considerando fatores como sexo e faixa etária. Em consonância, também foi realizado um estudo experimental, de caráter quanti-qualitativo, para avaliar o potencial citotóxico da (S)-(+) carvona e da (R)-(-)-carvona em linhagens celulares de CM. Assim, constatou-se que a TM por CM no Brasil apresenta uma tendência crescente ao longo dos anos, independe de sexo e faixa etária. No entanto, observou-se que no sexo feminino houve um maior número de mortes e, no sexo masculino, uma maior progressão da TM ao longo dos anos. Ademais, a amplificação da mortalidade por CM ocorreu em conformidade com o aumento da idade, revelando uma relação de proporcionalidade entre esses dois fatores. Com relação a análise experimental, constatou-se que tanto a (S)-(+) carvona como a (R)-(-)-carvona revelaram-se citotóxicas às linhagens celulares de $\mathrm{CM}$, apresentando um efeito dependente da concentração.

PALAVRAS-CHAVE: Neoplasias da mama. Taxa de Mortalidade. Citotoxicidade.

Graduanda em Enfermagem, Universidade Federal de Campina Grande, Cuité, Paraíba, Brasil. ORCID ID: 0000-0002-0082-0530

IIGraduado em Biotecnologia, Universidade Federal da Paraíba, João Pessoa, Paraíba, Brasil. II ORCID ID: 0000-0003-1992-2032 Enfermeira, Doutora em Biotecnologia, Universidade Federal de Campina Grande, Cuité, Paraíba,
58175-000. Autora correspondente. - e-mail: brunabdantas@gmail.com. ORCID ID: 0000-0001-8807-1601 


\section{INTRODUÇÃO}

O câncer posiciona-se atualmente como uma das principais causas de mortalidade, afetando populações de todas as regiões e países. ${ }^{1}$ Só no Brasil, estima-se que mais de 200 mil mortes, por essa causa, tenham ocorrido em 2015. Um valor que corresponde a aproximadamente $20 \%$ dos óbitos totais, para esse mesmo ano, e qualifica o Brasil como um dos países com a maior mortalidade por câncer do mundo. ${ }^{2}$ Nessa perspectiva, o Câncer de Mama (CM) representa o câncer mais comumente diagnosticado em mulheres e a principal causa de mortalidade por câncer em mulheres na maior parte do mundo. ${ }^{1}$ No Brasil, entre 2014 e 2017 mais de 135 mil mortes foram registradas em decorrência do CM, o que representa 15\% de todas as mortes por câncer ocorridas nesse período. 3

Apesar dos elevados índices da mortalidade por CM caracterizarem uma realidade comum a boa parte dos países do mundo, há uma dualidade existente entre países desenvolvidos e aqueles considerados subdesenvolvidos, ou em desenvolvimento, que necessita ser abordada. Isto é, enquanto a mortalidade por CM apresenta índices decrescentes, ao longo dos anos, nos países europeus e norte-americanos, os países latino-americanos e africanos demonstram o crescimento exacerbado dessas taxas, dispondo uma tendência progressiva ao longo das décadas. 4

Esse cenário decorre da implementação de melhorias em estratégias de prevenção secundária - que inclui a oferta de métodos de diagnóstico - e tratamento do CM que têm ocorrido nos países desenvolvidos, em consonância ao aumento da incidência da doença. No entanto, tais medidas não podem ser obser- vadas nos países em desenvolvimento e subdesenvolvidos, como o Brasil. 5 Assim, pode-se inferir que a Taxa de Mortalidade (TM) representa um importante indicador da qualidade da assistência, necessitando da realização de levantamentos frequentes, de modo a possibilitar a caracterização do comportamento desse índice, ao longo dos anos, e, consequentemente, apontando as lacunas e direcionado as melhorias no tocante a atenção a pessoa com CM. ${ }^{6}$

Ademais, considerando a elevação da incidência e mortalidade do CM e a necessidade de atender as especificidades da população afetada pela doença, a relevância da existência de múltiplas formas de tratamento do CM para a redução desse índice torna-se evidente. 7 Nesse sentido, os monoterpenos representam uma classe de produtos naturais com diversas atividades biológicas relatadas, dentre elas, a anticancerígena. ${ }^{8,9}$ A carvona, por sua vez, constitui um monoterpeno encontrado nos óleos essenciais de cominho (Carum carvi) e hortelã (Mentha spicata) - sendo a (S)-(+) carvona presente nesse primeiro e a (R)-(-) carvona no segundo - ambas as especiarias corriqueiras nas preparações culinárias brasileiras. Atualmente há disponível na literatura o registro das propriedades anticancerígenas da (S)-(+) carvona, no entanto, a ( $\mathrm{R})-(-)$-carvona ainda apresenta esse potencial desconhecido. ${ }^{10}$

Considerando essas informações, o presente estudo propõe-se a realizar dois objetivos: o primeiro, traçar o perfil da mortalidade por CM no Brasil entre 1987 e 2016 e o segundo, analisar o potencial citotóxico da (S)-(+) carvona e da (R)-(-)-carvona em linhagens celulares de CM. 


\section{MATERIAL E MÉTODOS}

Para atender o primeiro objetivo da pesquisa, realizou-se um estudo documental retrospectivo com abordagem quantitativa, acerca dos óbitos por câncer de mama CM, registrados no Atlas de Mortalidade Online do Instituto Nacional de Câncer (INCA). Foram consideradas as mortes ocorridas no Brasil entre 1987 e 2016, em mulheres e/ou homens, com idade entre o e mais de 99 anos.

Optou-se por avaliar o comportamento da taxa de mortalidade (TM) por CM entre 1987 e 2016, por este período permitir a análise ao longo de 3 décadas, além de fornecer um panorama recente acerca do comportamento desse índice no país. Ainda, optou-se por avaliar a TM por CM em ambos os sexos, considerando o aumento da incidência e da mortalidade da doença, tanto em homens como em mulheres. Por fim, optou-se por analisar uma faixa etária abrangente tendo em vista a idade como fator determinante reconhecido para o desenvolvimento da doença.

Inicialmente, analisou-se a TM por CM, ajustada para 100.000 homens e mulheres, com idade entre o e 99 anos e, entre 1987 e 2016, considerando o ajuste para a população do ano de 2000. Posteriormente, os dados foram analisados considerando a TM por CM ajustada para 100.000 homens ou mulheres, com idade entre o e mais de 99 anos, entre 1987 a 1996, 1997 a 2006 e 2007 a 2016, considerando o ajuste para a população dos anos de 1991, 2000 e 2010, respectivamente. Com base nos dados provenientes dessa etapa, calculou-se a progressão da mortalidade por CM de 2017 a 2107.

Por fim, realizou-se o levantamento da mortalidade por CM, ajustada para 100.000 homens e mulheres, nos intervalos de idade de 0 a 4, 5 a 9, 10 a 14, 15 a 19, 20 a 29, 30 a 39, 40 a 49, 50 a 59, 60 a 69, 70 a 79 e 80 ou mais anos, entre 1987 e 1996, 1997 e 2006 e 2007 e 2016, considerando o ajuste para a população dos anos de 1991, 2000 e 2010, respectivamente.

Os dados coletados no Atlas de Mortalidade Online do INCA foram, então, analisados no Software Prism GraphPad, versão 5,00, de modo a gerar gráficos que, por sua vez, possibilitaram a análise. Para esta etapa, não foram utilizados métodos estatísticos específicos, considerando que a análise foi meramente descritiva.

Para determinar o efeito anticâncer das substâncias propostas, atendendo ao segundo objetivo da pesquisa, fez-se necessária a realização de um estudo experimental, com abordagem quanti-qualitativa. Para a execução dos ensaios experimentais, por sua vez, foram utilizados os seguintes reagentes: RPMI, DEMEM, D-glicose, piruvato de sódio, Soro Bovino Fetal (SBF), penicilina, estreptomicina, tripsina, dimetilsulfóxido (DMSO), Dodecil Sulfato de Sódio (SDS), brometo de 3-(4,5-dimetiltiazol-2-il)-2,5-difeniltetrazolium (MTT), Hoechst 33342 (HO), lodeto de Propídio (IP), 5-fluorouracil, doxorrubicina, (S)-(+)-carvona e (R)-(-)-carvona.

Ademais, foram utilizadas as linhagens de células cancerígenas humanas MCF-7 (Adenocarcinoma Mamário Humano) e MDA-MB-231 (Adenocarcinoma Mamário Triplo Negativo Humano). A linhagem MCF-7 foi cultivada em meio RPMI-1640 e a MDA-MB-231 em DMEM com aditivo de 4,5 g/mL de D-glicose e $1 \mathrm{mM}$ de piruvato de sódio. Todas as linhagens foram suplementadas com 10\% de SBF, penicilina (1000 $\mathrm{U} / \mathrm{mL}$ ) e estreptomicina (100 $\mathrm{mg} / \mathrm{mL}$ ) e mantidas em incubadoras com atmosfera contendo $5 \%$ de $\mathrm{CO} 2$ a $37^{\circ} \mathrm{C}$. O meio de cultivo foi trocado de acordo com a confluência celular, sendo essas trocas realizadas quando a confluência observada se encontrava acima de $90 \%$.

No primeiro ensaio, buscou-se avaliar a viabilidade celular, utilizando, para este fim, a 
técnica de redução do MTT. Para tanto, as células MCF-7 e MDA-MB-231 foram cultivadas em placas de 96 poços na densidade de $3 \times 104$ células por poço e submetidas ao tratamento com a (S)-(+)-carvona e a (R)-(-)-carvona nas concentrações de 10, 5, 2,5 e 1,25 mM, durante 72 horas. Como substância controle foi utilizado o 5-fluorouracil. Seguido o tempo de tratamento, as placas foram centrifugadas a $200 \mathrm{~g}$ por $5 \mathrm{mi}$ nutos, o sobrenadaste foi parcialmente removido e a solução de $\mathrm{MTT}$ ( $5 \mathrm{mg} / \mathrm{mL}$ ) foi adicionada aos poços sendo incubadas por mais 4 horas. ${ }^{11}$ Subsequentemente, foi adicionado $100 \mu \mathrm{L}$ de $10 \% \mathrm{SDS} / \mathrm{HCl}(0.01 \mathrm{M})$ e as placas foram mantidas sob agitação pelo período de 12 horas. ${ }^{12}$

A absorbância a $570 \mathrm{~nm}$ foi mensurada utilizando espectrofotômetro. Três experimentos independentes foram realizados e analisados sob o teste one-way ANOVA, seguido do pós-teste Bonferroni, sendo considerados significativos valores de $\mathrm{p}<0,05$ em relação ao controle. Os valores da Concentração Inibitória Média ( $\mathrm{Cl50}$ ) foram obtidos por meio da curva de regressão não linear.

A integridade de membrana foi avalia-

\section{RESULTADOS E DICUSSÃO}

Os dados provenientes da primeira etapa de análise, que consideram a taxa de mortalidade por câncer de mama (TM/CM), independente do sexo e da faixa etária no Brasil, de 1987 a 2016, revelam que, no início do período de análise proposto, 1987, a TM por CM no Brasil foi de 3,89; ao fim desse período, 2016, o coeficiente passou a adotar o valor de 7,48, caracterizando um aumento de $48 \%$ ao longo de 30 anos (Figura 1).

A adoção de hábitos de vida predisponentes ao desenvolvimento do CM - da por meio da dupla marcação com IP e HO. Para isso, as células MCF-7 e MDA-MB-231 foram cultivadas sob lamínulas em placas de 6 poços, na densidade de $1 \times 103$ células por poço e tratadas com concentrações equivalentes a $\mathrm{Cl}_{50}$ da (S)-(+)-carvona e (R)-(-)-carvona para cada linhagem, por um período de 24 horas. Como substância controle, foi utilizada a doxorrubicina $(5 \mu \mathrm{g} / \mathrm{mL})$.

Após o tempo de incubação, as células foram fixadas com solução de ácido acético glacia e metanol (1:3), durante 10 minutos. Logo após, as células foram lavadas com tampão fosfato salina (PBS) por 3 vezes. Seguidamente as células foram marcadas com IP $(2 \mu \mathrm{g} / \mathrm{mL})$ e $\mathrm{HO}(1 \mu \mathrm{g} / \mathrm{mL})$, por 10 minutos e protegidos da luz. Após o período de marcação, as amostras foram lavadas com PBS por três vezes. Para captura das imagens foi utilizado o microscópio óptico, com ampliação de 200 vezes, do qual foi utilizado o comprimento de onda de excitação de $533 \mathrm{~nm}$ para IP e $350 \mathrm{~nm}$ para $\mathrm{HO}$ e exposição de $800 \mathrm{~ms}$. A análise dessa etapa foi realizada de forma meramente qualitativa, dispensando a utilização de métodos estatísticos. como o sedentarismo, a obesidade e o uso da contracepção oral e da terapia de reposição hormonal pós menopausa, tem se tornado cada vez mais frequentes na população brasileira. Em consonância a isso, a adoção de fatores de proteção - como a paridade e a amamentação -, tem se tornado cada vez mais restrita5,13. O cenário supracitado resultou no aumento da incidência do CM, e, consequentemente, a demanda de recursos destinados a essa área. Apesar disso, o financiamento atual da 
política a pessoa com CM no Brasil não acompanhou essa necessidade, além de não considerar as especificidades populacionais e a prevenção como principal estratégia no combate à doença, o que tem repercussões diretas na obtenção da cura e, por sua vez, reflete na elevação da mortalidade por essa causa e justifica os resultados deste estudo. ${ }^{2}$

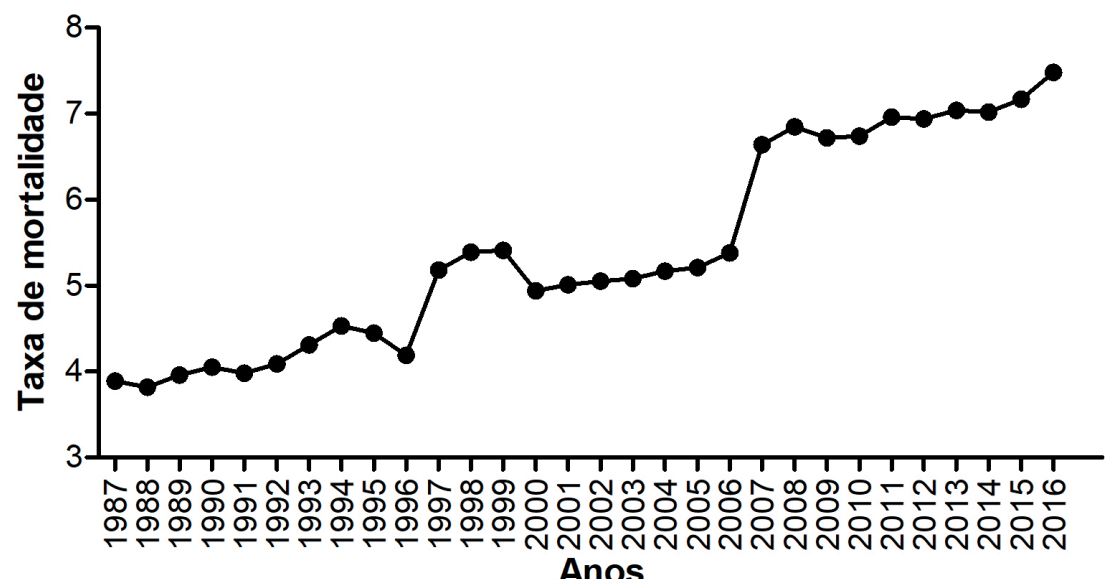

FIGURA 1 - Taxa de mortalidade por câncer de mama no Brasil, ajustada pela população brasileira de 2010, por 100.000, independente do sexo e da faixa etária, entre 1987 e 2016

Ademais, o fato dos países pertencentes à União Europeia - aos quais correspondem os maiores índices de mortalidade por $\mathrm{CM}$ do mundo - terem reduzido seus índices de mortalidade por CM ao implementar melhorias no diagnóstico e tratamento da doença, corrobora que a inabilidade assistencial representa a principal causa do aumento progressivo da mortalidade por CM no Brasil. 4

Observando a distribuição da TM/CM segundo o sexo, independente da faixa etária, no Brasil entre 1987 a 1996, 1997 a 2006 e 2007 a 2016, verificou-se que o coeficiente de mortalidade ajustado para o sexo feminino foi de 7,81 (entre 1987 a 1996), 9,60 (entre 1997 a 2006) e 12,75 (entre 2007 a 2016). Ou seja, houve um aumento de $18,75 \%$ entre o primeiro e o segundo período; $24,7 \%$ entre o segundo e o terceiro período; e quando comparado o primeiro e o terceiro período analisados, o aumento foi de $38,7 \%$ (Figura $2 \mathrm{~A}$ ).

Considerando o sexo masculino, o coeficiente de mortalidade foi de 0,06 (entre 1987 a 1996), 0,10 (de 1997 a 2006) e 0,18 (entre 2007 a 2016), o que implica um aumento de $40 \%$ entre o primeiro e o segundo período; $44 \%$ entre o segundo e o terceiro período. Quando comparado o primeiro e o terceiro período analisados, o aumento foi de $66,7 \%$ (Figura $2 \mathrm{~A}$ ).

Considerando o sexo masculino, $\mathrm{O}$ coeficiente de mortalidade foi de 0,06 (entre 1987 a 1996), 0,10 (de 1997 a 2006) e 0,18 (entre 2007 a 2016), o que implica um aumento de $40 \%$ entre o primeiro e o segundo período; $44 \%$ entre o segundo e o terceiro período. Quando comparado o primeiro e o terceiro período analisados, o aumento foi de $66,7 \%$ (Figura $2 \mathrm{~A}$ ). 

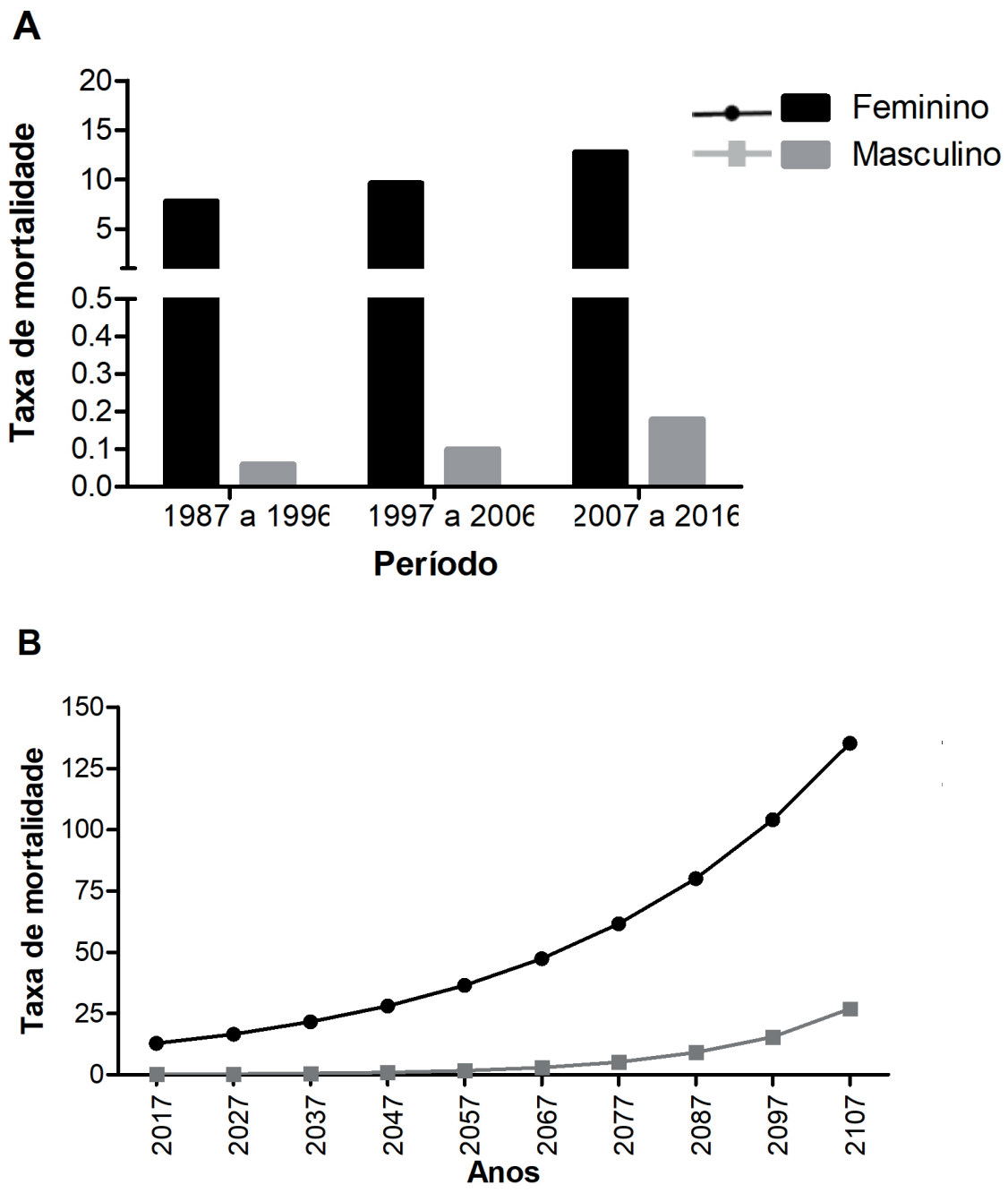

FIGURA 2 - Taxa de mortalidade por câncer de mama no Brasil, ajustada pela população brasileira de 1991 (entre os anos de 1987 a 1696), 2000 (entre os anos de 1997 a 2006) e 2010 (entre os anos de 2007 a 2016), por 100.000 homens ou mulheres (A). Progressão da taxa de mortalidade por câncer de mama no Brasil em 90 anos, segundo o sexo e por período selecionado, valores ajustados para cada 100.000 homens ou mulheres (B)

Considerando o sexo masculino, o coeficiente de mortalidade foi de 0,06 (entre 1987 a 1996), 0,10 (de 1997 a 2006) e 0,18 (entre 2007 a 2016), o que implica um aumento de $40 \%$ entre o pri- meiro e o segundo período; $44 \%$ entre o segundo e o terceiro período. Quando comparado o primeiro e o terceiro período analisados, o aumento foi de $66,7 \%$ (Figura $2 \mathrm{~A}$ ). 
Ao estimar a progressão da mortalidade por CM de 2017 a 2107, considerando os valores oriundos da segunda etapa de análise, percebe-se que, se o contexto assistencial do CM no Brasil permanecer o mesmo, em 2107 a mortalidade por essa doença estará em torno dos 135,16 no sexo feminino e 26,90 no sexo masculino. Isso caracteriza um aumento de $90,3 \%$ no sexo feminino e $99,3 \%$ no sexo masculino (Figura 2B).

Como já observado no item anterior, o aumento progressivo da mortalidade por CM no Brasil é um reflexo da elevação da incidência da doença, associada a existência de lacunas na assistência a pessoa com CM no Brasil.5,13 Isso justifica a progressão desse índice sobretudo no sexo feminino. No entanto, no sexo masculino esse aumento ocorre de modo mais expressivo, fomentando a ideia da existência de especificidades, inerentes a esse grupo, que necessitam serem discutidas de modo a justificar esse cenário.

Nesse sentido, o principal fator a ser discutido envolve o modelo hegemônico de masculinidade que tem influência direta na busca tardia dos serviços de saúde pelos homens e que, por sua vez, relaciona-se com diagnóstico do $\mathrm{CM}$, quando este encontra-se em estágios avançados, diminuindo significativamente as chances de sobrevida a doença e aumentando a mortalidade por essa causa. ${ }^{14}$

Ademais, o manejo assistencial da doença é pouco específico para a população masculina, o que culmina na progressão da mortalidade mais que no sexo feminino, em que, apesar dos obstáculos assistenciais, as linhas de cuidados são bem estabelecidas. 15,16,17

$O$ resultado referente a estimativa da progressão da mortalidade por CM de 2017 a 2107 reitera a necessidade de se intervir com melhorias na assistência a pessoa com CM no Brasil, ao passo que revela a carência do público masculino de ser visto nesse âmbito assis- tencial. Nesse sentido, a sensibilização da população por meio da educação em saúde, com ênfase no público masculino, mostra-se como uma importante ferramenta para a redução do índice de mortalidade e o não cumprimento dessa estimativa.

Ao considerar a TM por $\mathrm{CM}$, segundo a faixa etária e o sexo no Brasil, entre 1987 a 1996, 1997 a 2006 e 2007 a 2016, observou-se que a mortalidade por CM no Brasil tem registros a partir dos 10 anos, para o sexo feminino e dos 30 anos, para o sexo masculino. No entanto, a partir dos 30 e 40 anos, os índices relativos a mortalidade tornam-se mais expressivos, respectivamente, nos homens e nas mulheres (Figura 3).

No sexo feminino, entre os 30 e 39 anos - idade em que há um maior número de mortes - o coeficiente de mortalidade foi de aproximadamente 5,21 e, a partir dos 80 anos, de 88,56 (Figura 3A). Com o sexo masculino, por sua vez, entre os 40 e 49 anos, a mortalidade foi de aproximadamente 0,20 e, a partir dos 80 anos, de 1,84 (Figura 3B). Dessa forma, verifica-se que há uma relação de proporcionalidade entre o aumento da idade e mortalidade que independe do sexo.

Acredita-se que esses resultados estejam associados a relação de proporcionalidade existente entre o número de anos vividos e a maior exposição a fatores de risco extrínsecos. Além disso, sabe-se que o envelhecimento representa uma condição que fragiliza o organismo, tornando as chances de sobrevida a doença limitadas, a depender do tipo do tumor. ${ }^{2}$

Tendo sido comprovado que, independente do sexo e da faixa etária, a mortalidade por CM no Brasil tem adotado um perfil crescente ao longo dos anos, corrobora-se a necessidade de se buscar novas formas de prevenção e tratamento eficazes e acessíveis economicamente a população. 


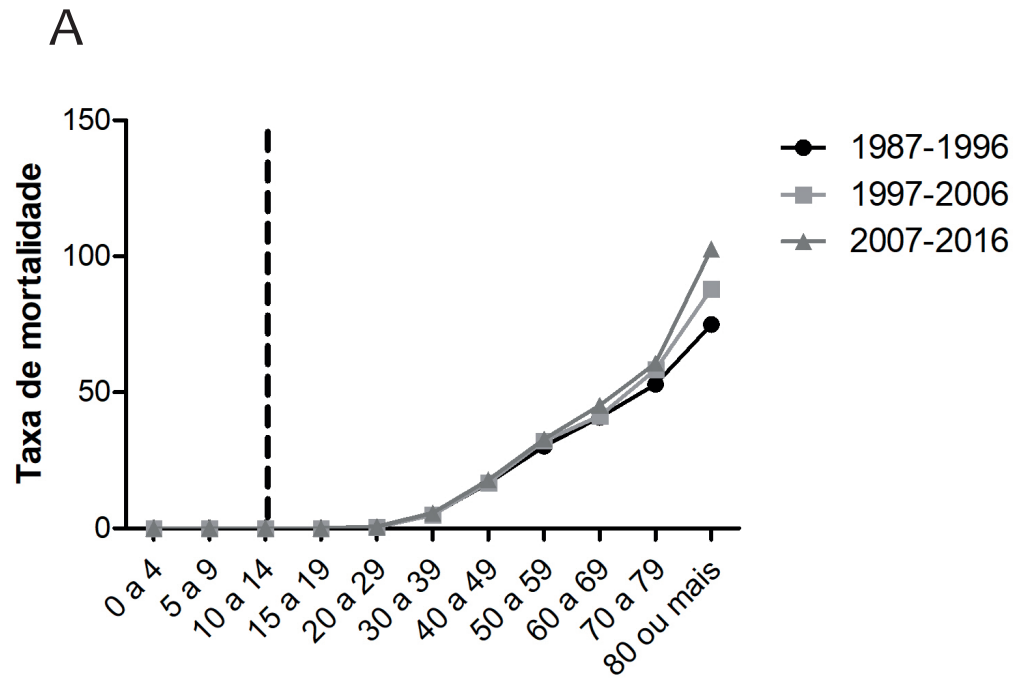

B

Faixa etária

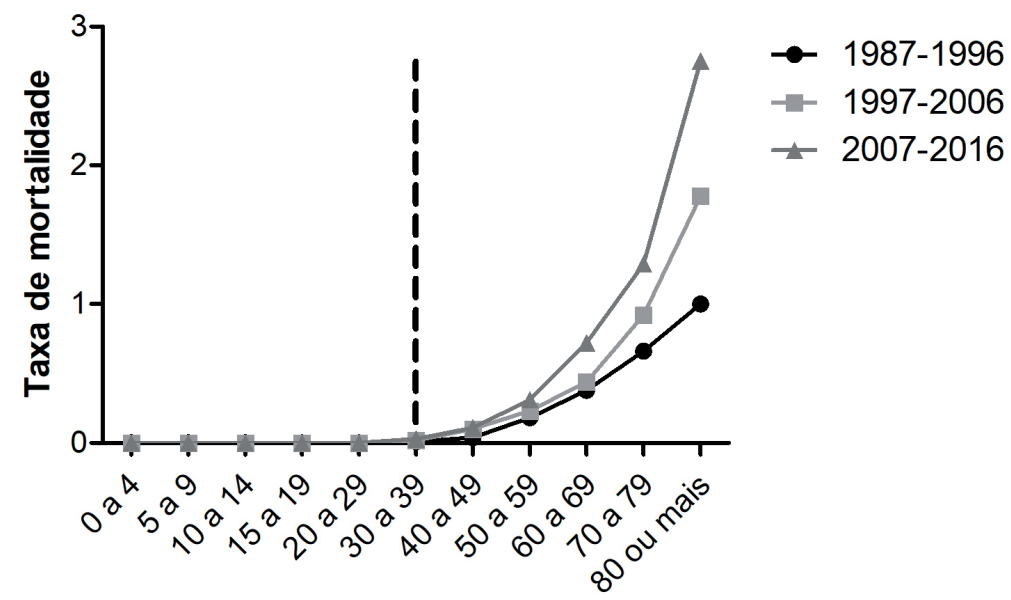

Faixa etária

FIGURA 3 - Distribuição da taxa de mortalidade por câncer de mama no Brasil segundo a faixa etária no sexo feminino (A) e no sexo masculino (B) nos períodos de 1987 a 1996, 1997 a 2006 e 2007 a 2016, para cada 100.000 mulheres ou homens

Por isso, foi avaliado o efeito citotóxico da (S)-(+)-carvona e da (R)-(-)-carvona em MCF-7 e MDA-MB-231, linhagens celulares humanas cancerígenas de mama sensíveis e resistentes, respectivamente, à terapia hormonal.

Para determinar o efeito da (S)-(+)-arvona e da (R)-(-)-carvona na redução do metabolismo e, consequentemente, da viabilidade celular, utilizou-se o ensaio de redução do MTT, sendo os dados do experimento expressos como valor de $\mathrm{Cl}_{50}$. Assim, determinou-se que a Cl50 da MDA-MB-231 foi de 2,76 mM pela (S)-(+) carvona e 2,03 mM, pela (R)-(-) carvona; na MCF7, por sua vez, foi de $3,18 \mathrm{mM}$ pela $(S)-(+)$ carvona) e 2,18 mM pela (R)-(-) carvona (Tabela 1). 
TABELA 1: Cl50 \pm Erro Padrão da Média (EPM) das linhagens celulares MDA-MB-231 e MCF-7 após 72 horas de tratamento com a (S)-(+) carvona e (R)-(-) carvona

\begin{tabular}{ccccc}
\hline \hline TRATAMENTO & & 16 MDA-MB-231 & MCF-7 \\
\cline { 1 - 1 } (S)-(+) carvona & & $2,76 \pm 3,99 \mathrm{mM}$ & $3,18 \pm 1,08 \mathrm{Mm}$ \\
(R)-(-) carvona & & $2,03 \pm 2,55 \mathrm{mM}$ & $2,18 \pm \mathrm{mM}$ \\
\hline \hline
\end{tabular}

Esses resultados permitem constatar que ambos os isômeros reduziram a viabilidade das linhagens estudadas, fornecendo, assim, um indicativo de citotoxicidade. Ademais, foi observado que, em ambas as linhagens estudadas, a redução da viabilidade celular induzida pelos isômeros da carvona ocorreu em função do aumento da concentração, o que caracteriza uma ação dependente da concentração.

Importa ressaltar que as linhagens MDA-MB-231 e MCF-7 são, respectivamente, sensíveis e resistentes a terapia hormonal, o que significa dizer que os produtos naturais analisados neste estudo demonstraram-se promissores ao desenvolvimento de uma nova terapia química contra o $\mathrm{CM}$, tendo em vista que as linhagens celulares estudadas representam tanto tipo de CM com melhores prognóstico como os de pior. 5

Alguns estudos corroboram com esses resultados ao apontar a bioatividade anticancerígena de compostos dos quais a carvona faz parte. ${ }^{18,19}$ De forma específica, a atividade citotóxica da (R)-(-)-carvona foi relatada em linhagens de MDA-MB-231 e MCF-7, revelando, ao mesmo tempo, a não citotoxicidade da substância em linhagens humanas não cancerígenas10. Ademais, um ensaio in vivo realizado com a (S)-(+) carvona e a (R)-(-) carvona revela a baixa toxicidade aguda de ambos os isôme- ros20. Sendo assim, importa ressaltar o ineditismo desta pesquisa, tendo em vista que os resultados discutidos trazem, pela primeira vez, a comparação do efeito dos dois isômeros da carvona.

Com a finalidade de confirmar a morte das linhagens cancerígenas, realizou-se o ensaio de marcação com Hoechst ( $\mathrm{HO}$ ) e lodeto de Propídeo (IP). A partir dele, verificou-se que todas as células foram marcadas com o $\mathrm{HO}$, tendo em vista que o fluoróforo consiste em um marcador nuclear, que atravessa a membrana celular independente dela estar rompida, ou seja, independente da viabilidade celular. ${ }^{21,22}$

Com relação ao IP, verificou-se que a maioria das células de MDA-MB-231 assim como de MCF-7 foram marcadas por esse fluoróforo. Essa marcação só é possível em condições que promovem o rompimento da membrana celular, o que permite a ligação do IP com o material genético e confirma a morte das células e, consequentemente, a citoxicidade da (S)-(+)-carvona e da (R)-(-)-carvona carvona em ambas as linhagens (Figura 4 ). ${ }^{21}$

Os resultados obtidos no presente estudo convergem com as informações de outros, nos quais o processo de morte por apoptose foi sugerido em compostos dos quais a carvona faz parte e na (R)-(-)-carvona de forma específica. ${ }^{10,18,19}$ 

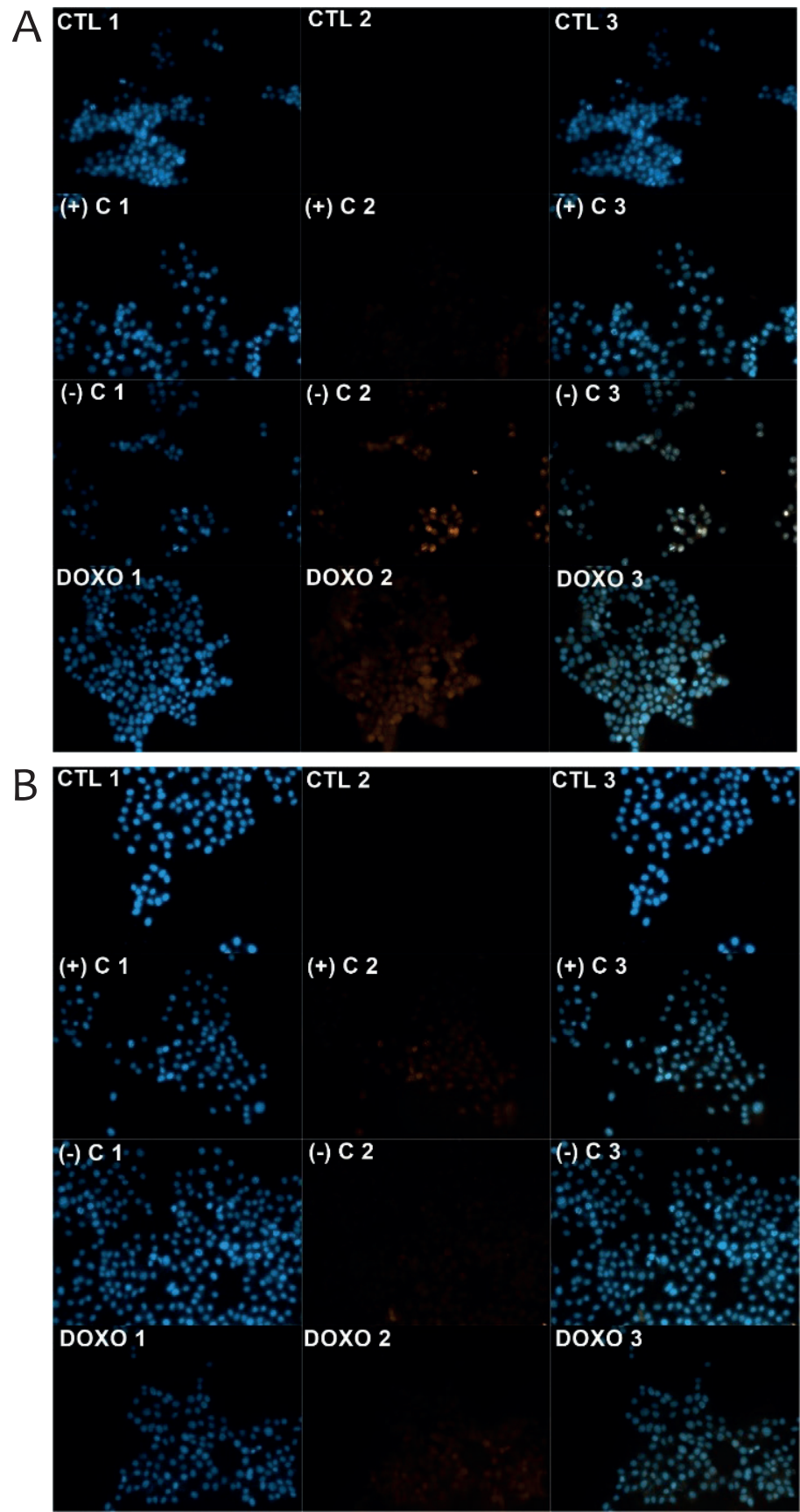

FIGURA 4 - Resultados da marcação com HO e IP em células MDA-MB-231 (A) e MCF-7 (B) não tratadas (CTL) e após 24 horas de tratamento com a (S)-(+) carvona $((+) C),(R)-(-)$ carvona $((-) C)$ e Doxorrubicina (DOXO) 


\title{
CONCLUSÕES
}

Com relação ao perfil da mortalidade por CM no Brasil, entre 1987 e 2016, constatou-se que o indicador apresentou um comportamento crescente ao longo do período analisado em ambos os sexos. Considerando a especificação por sexo, verificou-se que ao sexo feminino corresponderam os valores mais elevados, no entanto, no sexo masculino o aumento foi mais expressivo. Acerca da especificação por faixa etária, observou-se que os valores aumentam em conformidade a idade, especialmente a partir dos 30 anos para as mulheres e 40 anos para os homens.

A partir da realização do estudo experimental, corroborou-se o potencial anticâncer da (R)-(-)-carvona previamente já relatado em outros estudos, além do que constatou-se esse potencial também na (S)-(+) carvona. Nesse sentido, verificou-se que há uma citotoxicidade em linhagens celulares humanas

\section{AGRADECIMENTOS}

As instituições de fomento à pesquisa nacional (CNPq e CAPES) que em outras épocas mantinham, aliado ao governo, a capacidade de incentivar a pesquisa e permitir a produ- ção de trabalhos como este. E ao Professor Dr. Demetrius Antonio de Araújo pelo acolhimento em seu laboratório para realização de parte deste trabalho.

\section{BREAST CANCER: MORTALITY ANALYSIS AND TREATMENT PERSPECTIVE}

\begin{abstract}
The mortality rate (MR) is one of the majors quality indicators of breast cancer $(B C)$ medical assistance, proving to be a fundamental tool to outline and review health politics directed to people affected by this disease. Moreover, therapeutic approach represents one of the most important segments to reduce its mortality. Thus, the aim of this study is to characterize the mortality profile of BC in Brazil, as well as to propose a new therapeutic alternative based on the use of natural products. For this, a retrospective documentary study was performed, describing the distribution of MR by BC in Brazil, from 1987 to 2016, considering factors such as gender and age group; Accordingly, a quantitative and qualitative experimental study was also performed to evaluate the cytotoxic potential of $(S)-(+)$ carvone and (R) - (-) - carvone in BC cell lines. Thus, it was found that MR by BC in Brazil presents a growing trend over the years, regardless of gender and age group. However, it was observed that in women there was a higher number of deaths and in men, a greater progression of MR over the years. In addition, the amplification of mortality due to $\mathrm{BC}$ occurred as age increased, revealing a proportionality relationship between these two factors. Regarding the experimental analysis, it was found that both (S) - (+) carvone and (R) - (-) carvone were cytotoxic to $B C$ cell lines, presenting a concentration-dependent effect.
\end{abstract}

KEYWORDS: Breast Neoplasms. Rate mortality. Cytotoxicity. 


\section{REFERÊNCIAS}

1. Stewart BW, Wild CP, organizadores. Word Cancer Report (2014). Genebra: Public Health Well; 2018 [acesso em 25 Nov. 2018]. Disponível em: http://www.thehealthwell.info/ node/725845.

2. Instituto Nacional de Câncer José Alencar Gomes da Silva. Estimativa 2014: Incidência de câncer no Brasil. Rio de Janeiro: INCA; 2014 [acesso em 19 Mai. 2019]. Disponível em: https://www. inca.gov.br/bvscontrolecancer/publicacoes/Estimativa_2014.pdf.

3. Figueiredo FD, Almeida TCDC, Cardial DT, Maciel EDS, Fonseca FLA, Adami, F. The role of health policy in the burden of breast cancer in the burden of breast cancer in Brazil. BMC Women's Health. 2017 Nov; 15(1):121.

4. Carioli G, Malvezzi M, Rodriguez T, Bertuccio $P$, Negri E, Vecchia CL. Trends and predictions to 2020 in breast cancer mortality in Europe. Breast. 2017 Dez; 36(1):89-95.

5. Torre LA, Bray F, Siegel RL, Ferlay ME, Lortet-Tieulent J, Ahmedin J. Global cancer statistics. CA: A CA J Clin. 2012 Fev; 65(2):87-108.

6. Li C, Wang P. An age-period-cohort analysis of female breast cancer mortality from 1990-2009 in China. Int J Equity Health. 2015 Set; 14(76).

7. Rocha-Brischiliari C, Oliveira RR, Andrade L, Brischliari, Gravena AAF, Carvalho MDB, Pelloso $\mathrm{SM}$. The rise in mortality from breast cancer in Young women: trend analysis in Brazil. PLoS One. 2017 Jan; 12(1).

8. Suntres ZE, Coccimiglio J, Alipour M, The bioactivity and toxicological actions of carvacrol.
Crit Rev Food Sci Nutr. 2014 Set; 55(3):304-18.

9. Almeida, RR. Mecanismos de ação dos monoterpenos aromáticos: timol e carvacrol [monografia]. São João del-Rei; 2015.

10. Patel PB, Thakkar VR. L-carvone induces P53, caspase 3 mediated apoptosis and inhibits the migration of breast cancer cell lines. Nutr Cancer. 2014 Mar; 66(3):453-462.

11. Mosmann T. Rapid colorimetric assay for cellular growth and survival: application to proliferation and cytoxicity assays. Journal ImmunolMethods. 1983 Dez; 65(1-2):55-63.

12. Tada H, Shiho O, Koroshima K, Koyama M, Tsukamoto K. An improved colorimetric assay for interleukin 2. Journal Immunol Methds. 1986 Nov; 93(2):157-65.

13. Chelebowski RT, Manson JE, Garnet LA, Cauley JA, Aragaki AK, Stefanick ML et al. Estrogen plus progestin and breast cancer incidence and mortality in the Women's Health Initiative Observational Study. J Natl Cancer Inst. 2014 Abr; 105(8):526-35.

14. Connel RW, Messerschmidt JM. Masculinidade hegemônica: repensando o conceito. Rev Estud Fem. 2014 Abr; 21(1):241-282.

15. Anderson WF, Jatoi I, Rosenberg PS. Male breast cancer: a population-based comparison with female breast cancer. J Clin Oncol. 2010 Jan; 10(2):232-39.

16. Giordano SH, Cohen DS, Buzdar AU, Perkins $\mathrm{G}$, Hortobagyi GN. Breast cancer in men: a population-based study. Cancer. 2014 Mai; 101(1):51-7. 
revista de $\mathbf{N O V} \mathbf{A}$

da saúde ESPERANÇA

17. Goss PE, Reid C, Pintilie M, Miller N. Male breast carcinoma: a review of 229 patients who presented to the Princess Margaret Hospital during 40 years: 1955-1996. Cancer. $1999 \mathrm{Fev} ; 85$ (3):62839.

18. Mollazadeh $\mathrm{H}$, Afshari AR, Hosseinzadeh $\mathrm{H}$. Review on the potential therapeutic roles of nigella sativa in the treatment of patients with cancer: involvement of apoptosis: black cumin and cancer. J pharmocopuncture. 2017 Set; 20(3):158-72.

19. Sharopov F, Valiev A, Satyal P, Gulmurodov I,
Yusufi S, Setzer WN, Wink M. Cytotoxicity of the essential oil of fennel (Foeniculum vulgare) from Tajikistan. Foods. 2017 Ago; 6(9).

21. Crowley LC, Marfell BJ, Waterhouse NJ. Analyzing cell death by nuclear staining with Hoechst 33342. Cold Spring Harb Protoc. 2016 Ago; 1(9).

22. Crowley LC, Scott AP, Marfell BJ, Boughaba JÁ, Chojnowski G, Waterhouse NJ. Measuring Cell Death by Propidium lodide Uptake and $\mathrm{Cy}$ tometry. Cold Spring Harb Protoc. 2016 Jul; 1(7). população LGBT. Rev. Sau. Soc. 2018; 27(4): 112033. 